\title{
Results from the Healthy Active Kids South Africa 2018 Report Card
}

\author{
C E Draper, ${ }^{1,2} \mathrm{PhD}$; S A Tomaz, ${ }^{2} \mathrm{PhD}$; S H Bassett, ${ }^{3} \mathrm{PhD}$; J Harbron, ${ }^{4} \mathrm{PhD}$; H S Kruger, ${ }^{5} \mathrm{PhD}$; L K Micklesfield, ${ }^{1,2} \mathrm{PhD}$; \\ A Monyeki, ${ }^{6} \mathrm{PhD}$; E V Lambert, ${ }^{2,7} \mathrm{PhD}$; and members of the HAKSA 2018 Scientific Advisory Group
}

\begin{abstract}
${ }^{1}$ SA MRC Developmental Pathways for Health Research Unit, School of Clinical Medicine, Faculty of Health Sciences, University of the Witwatersrand, Johannesburg, South Africa

${ }^{2}$ Division of Exercise and Sports Medicine, Department of Human Biology, Faculty of Health Sciences, University of Cape Town, South Africa ${ }^{3}$ Department of Sport, Recreation and Exercise Science, Faculty of Community and Health, University of the Western Cape, Cape Town, South Africa ${ }^{4}$ Division of Human Nutrition, Department of Human Biology, Faculty of Health Sciences, University of Cape Town, South Africa ${ }^{5}$ Centre of Excellence for Nutrition, Faculty of Health Sciences, North-West University, Potchefstroom, South Africa

${ }^{6}$ Physical Activity, Recreation and Sport Sciences Research Focus Area, Faculty of Health Sciences, North-West University, Potchefstroom, South Africa ${ }^{7}$ Health through Physical Activity, Lifestyle and Sport Research Centre, Faculty of Health Sciences, University of Cape Town, South Africa
\end{abstract}

Corresponding author: C E Draper (catherine.draper@wits.ac.za)

\begin{abstract}
Background. Healthy Active Kids South Africa (HAKSA) Report Cards were produced in 2007, 2010, 2014 and 2016.
Objective. The 2018 Report Card aims to report on the latest available evidence relating to the physical activity (PA), nutrition and body composition of South African (SA) children and adolescents.

Methods. A review was conducted using the following databases: PubMed; Africa Journals Online; and Africa-Wide (EBSCOhost). Articles published from January 2016 to September 2018 were included for review by the HAKSA scientific advisory group. Data were extracted, and a grade for each indicator was assigned based on the available evidence and the consensus of the scientific advisory group. This included 12 PA indicators, 6 nutrition indicators and 3 body composition indicators.

Results. There was no evidence of a significant change in any of the indicators since the 2016 Report Card. Grades for certain indicators have been downgraded (from 2016) to bring these to the attention of relevant stakeholders and industry. These include food insecurity and grades that relate to the implementation of policy on PA and nutrition in the school environment, and on advertising and media relating to nutrition.

Conclusion. Key priorities for action include: safe opportunities for physical activity; minimising the gap between policy and implementation (school culture and environment, and government strategies); and the double burden of over- and undernutrition, which relates to the continuing concern about food insecurity in SA. There is a need for further research, including surveillance, on all indicators, for future Report Cards.
\end{abstract}

S Afr J Child Health 2019;13(3):130-136. https://doi.org/:10.7196/SAJCH.2019.v13.i3.1640

Physical activity (PA) is beneficial for the physical and mental health of children and adolescents $(0-17$ years old $),{ }^{[1,2]}$ while higher levels of sedentary behaviour (particularly screen time) are associated with unfavourable health outcomes. ${ }^{[3,4]}$ Nutrition has been recognised as a factor contributing to the development of overweight/obesity in children and adolescents. ${ }^{[5]} \mathrm{A}$ nutrient-dense diet and regular PA are beneficial for overall child growth, health and wellbeing. ${ }^{[6]}$ Healthy lifestyle behaviours also play a role in cognitive development and school achievement in children and adolescents. ${ }^{[7]}$

The Healthy Active Kids South Africa (HAKSA) Report Card reviews the most current evidence on the PA, nutrition and body composition of South African (SA) children and adolescents. This evidence provides the basis from which to guide policy, develop interventions and programmes and strengthen advocacy to create healthy environments and support healthy nutrition and PA, and discourage sedentary behaviours in SA children and adolescents. Children and adolescents ( 0 - 19 years old) make up 39\% of the total population of SA ( 52 million people in total) ${ }^{[8]}$ Although this proportion of children and adolescents is relatively high, it is lower than those in some other African countries: the proportion of children and adolescents 0 - 14 years old (a narrower age range) is also $39 \%$ in Zimbabwe (population 13.8 million), and in Nigeria the proportion of 0 - 14 year olds is $43 \%$ (population $~ 190.6$ million). ${ }^{[9]}$

Results from the HAKSA 2016 Report Card indicated that more than $50 \%$ of SA children were meeting PA recommendations, and government policies for the support of sport and PA in children and adolescents were evident. Areas of concern were high amounts of screen time and sedentary behaviour, as well as low fruit and vegetable consumption, and high intake of sugar-sweetened beverages (SSBs) and fast foods. Undernutrition and overweight/obesity were highlighted as a concern, as overweight prevalence was increasing, ${ }^{[10]}$ and the HAKSA 2016 Report Card highlighted the persistence of the double burden of under- and over-nutrition across South Africa. ${ }^{[1]}$ The HAKSA 2018 Report Card is the fifth in the series (since 2007), ${ }^{[10-12]}$ and aims to report on the available evidence relating to PA, sedentary behaviours, nutrition and body composition of SA children and adolescents (3 18 years old) published since the 2016 Report Card. In addition, we consider the related environmental and ecological factors that may be barriers to or facilitators for healthy eating and PA in SA children and adolescents.

\section{Methods}

The HAKSA 2018 Report Card has been developed and produced by a scientific advisory group consisting of 29 academics and/or content experts, with group leaders for physical activity, nutrition, body composition and early childhood content (in the context of this article, 'early childhood' refers to preschool-aged children, or those aged between 3 and 5 years old). Comprehensive searches on PubMed, Africa Journals Online, Africa-Wide Information (hosted by EBSCO) databases for evidence published from January 2016 - 
September 2018 on PA, nutrition and body composition in SA children and adolescents (3 - 18 years old) were conducted. Exclusion criteria were (i) review articles; (ii) studies in which the participants were exclusively over 18 years old; (iii) studies conducted outside of SA; and (iv) articles included in previous Report Cards. The HAKSA 2018 Report Card comprises 3 categories of indicators: PA, nutrition and body composition (Table 1). The PA indicators are aligned to a larger, international initiative, the Active Healthy Kids Global Alliance, which involves 49 countries. ${ }^{[13]}$ Data from these countries are harmonised for comparison.

The search yielded 805 titles, of which 62 were extracted for consideration (35 PA, 14 nutrition, 7 body composition and 9 early childhood (covering PA and body composition), with some overlap between different indicators). In addition, hand-searching was conducted by members of the scientific advisory group. Members of the group were each assigned between 2 and 4 full manuscripts to critically appraise ${ }^{[14]}$ Key study methods and findings relevant to the indicators were extracted and submitted to group leaders, who then summarised the findings for their theme. Where necessary, cross-checking of extracted data was done by the group leaders and first author of the present article. Content groups were asked to compile a summary report and to propose grades (with justification) for each indicator, taking into consideration the grades assigned in the HAKSA 2016 Report Card, to assess whether any improvements had occurred. ${ }^{[10]}$ These grades were then discussed in order to reach consensus within each group, and all groups were provided with an opportunity to comment on them so that there was consensus on all grades within the scientific advisory group.

Meetings were held in person and online to reach consensus on the grade assignment. Grades were assigned to each indicator within each of the four categories, ranging from A to F (Table 2), and a rationale for each grade was constructed.

\section{Results}

Most of the indicators were informed by smaller regional studies, as the only national data available for the past 2 years related to active transportation, the National School Nutrition Programme (NSNP), food security and body composition. Tables 3 - 5 provide the grade and a rationale for each indicator within the categories of $\mathrm{PA}$, nutrition and body composition, respectively. A full reference list is available on request from the authors. Table 6 presents grades assigned for the 2014, 2016 and 2018 Report Cards, to indicate progress or lack thereof.

\section{Discussion}

There was no evidence of improvements or declines since 2016 in any of the PA, nutrition and body composition indicators included in the

\section{Table 1. HAKSA 2018 Report Card grade categories and indicators}

\begin{tabular}{|c|c|}
\hline Category & Indicator \\
\hline Physical activity & $\begin{array}{l}\text { - Overall physical activity } \\
\text { - Early childhood physical activity } \\
\text { - Organised sport participation } \\
\text { - Active play } \\
\text { - Active transportation } \\
\text { - Sedentary behaviours } \\
\text { - Early childhood sedentary behaviour } \\
\text { - Physical fitness } \\
\text { - Family and peers } \\
\text { - School } \\
\text { - Community and environment } \\
\text { - Government }\end{array}$ \\
\hline Nutrition & $\begin{array}{l}\text { - Fruit and vegetable intake } \\
\text { - Snacking, SSBs, dietary sodium, fast food intake } \\
\text { - School nutrition culture and environment: tuck shops, vegetable gardens and } \\
\text { nutrition education } \\
\text { - NSNP } \\
\text { - Food security } \\
\text { - Advertising and media }\end{array}$ \\
\hline Body composition & $\begin{array}{l}\text { - Overweight/obesity } \\
\text { - Undernutrition } \\
\text { - Early childhood body composition }\end{array}$ \\
\hline
\end{tabular}

HAKSA = Healthy Active Kids South Africa; SSB = sugar-sweetened beverage; NSNP = National School Nutrition Programme.

Table 2. HAKSA grade descriptions

\begin{tabular}{ll}
\hline Grade $^{\star}$ & Description \\
\hline A & Succeeding with a large majority of children and youth $(81-100 \%)$ \\
B & Succeeding with well over half of children and youth $(61-80 \%)$ \\
C & Succeeding with about half of children and youth $(41-60 \%)$ \\
D & Succeeding with less than half, but some, children and youth $(21-40 \%)$ \\
F & Succeeding with very few children and youth $(0-20 \%)$ \\
INC & Inconclusive owing to insufficient data \\
HAKSA = Healthy Active Kids South Africa. \\
${ }^{*}$ When deciding on grades, certain grades were 'minus' grades (e.g. C-) if they were believed not to fully meet the criteria for the given grade (C), but also did not meet the \\
criteria for a lower grade.
\end{tabular}


Table 3. HAKSA 2018 PA grades and rationale

\begin{tabular}{lll}
\hline PA indicator & Grade & Rationale \\
\hline Overall PA & C & A study that objectively measured PA (ISCOLE, 9 - 11 years old), and another using self-report, indicated that \\
& $48-51.7 \%$ of SA children are meeting the 1 hour of MVPA per day recommendation. ${ }^{[15-17]}$ In these studies, \\
& mean (standard deviation) daily MVPA ranged from $56.6(23.4)$ to $64.9(25.5)$ minutes. Other self-report \\
& studies reported higher levels of meeting PA recommendations. ${ }^{[18-20]}$ Other evidence highlights that higher PA \\
& levels are associated with a lower likelihood of obesity ${ }^{[16]}$ better quality of life, ${ }^{[20]}$ better motor performance $e^{[19]}$ \\
& and reduced likelihood of using tobacco and marijuana. ${ }^{[1]}$ Since there is no new evidence indicating that overall \\
& PA levels are improving, the grade remains a C.
\end{tabular}

Early childhood PA A- Using previous PA guidelines (180 minutes per day of total PA) ${ }^{[22]} 100 \%$ of preschool-aged children reportedly met the recommendations in one study. ${ }^{[23]}$ In terms of new guidelines (180 minutes per day including 60 minutes of 'energetic play'), ${ }^{[24,25]} 78.2 \%$ of pre-schoolers from rural SA met guidelines. ${ }^{[26]}$ New evidence reinforces previous findings ${ }^{[10]}$ that gross motor skills proficiency in preschool-aged children in SA is adequate, and in some instances superior compared to available norms. ${ }^{[23,26,27]}$ However, several barriers to preschool-aged children engaging in PA or 'active play' have been reported, including: crime; lack of resources; lack of space; and facilities. ${ }^{[28-30]}$ Parents in high-income areas perceived screen-based technology as a significant barrier to preschool children being physically active. ${ }^{[29]}$ A grade of A- is therefore assigned. Organised sport
participation Active play

Active transportation

Sedentary behaviours $\mathrm{F}$

Early childhood sedentary behaviour

Physical fitness Family and peer support

School

Community and environment

Government
D The grade remains a D since there are no apparent changes in levels of participation, and there is no evidence of new interventions, strategies or policies to improve participation.

INC Data used for the overall PA and early childhood PA suggest that active play may be taking place despite some challenges (e.g. safety). Researchers have reported on important contextual information (e.g. resourcefulness, social interaction, play objects, play environment); ${ }^{[30]}$ however, we still do not have a concrete measure of active play. The grade therefore remains inconclusive.

C There is no evidence to suggest that active transportation has improved. Many (81\%) children and adolescents (6 - 15 years old) walk to school without adult supervision in low-income settings, and safety remains a concern $^{[31,32]}-61 \%$ of parents report being uncomfortable with their child walking to school, ${ }^{[32]}$ but are not necessarily in a position to improve this situation. Initiatives to improve the safety of active transportation have been trialled in certain regions; however, there are issues around sustainability and feasibility. The grade therefore remains a $\mathrm{C}$.

F There is no evidence to suggest that screen-time use is decreasing, and may in fact be getting worse as smart phones become more accessible and affordable. Furthermore, evidence indicates links between screen-based social networking and risky behaviours in adolescents. ${ }^{[33]}$ Data from ISCOLE indicates that 9 - 11-year-old children are spending an average of 3.3 hours on screens per day, with only $34 \%$ of children meeting the screentime guideline of $<2$ hours per day. ${ }^{[16,17]}$ Based on the available evidence of screen time not decreasing, and the potential risks of excess screen time in adolescents, the grade remains an $\mathrm{F}$.

INC Children attending preschools in low- and high-income urban areas spend approximately $73 \%$ of the preschool day sedentary, ${ }^{[23]}$ which is similar to children in rural areas $(70 \%){ }^{[26]}$ The percentage of preschool children in a rural, lowincome setting meeting screen-time guidelines ( $<1$ hour per day) $)^{[24,25]}$ was $98 \%$ (parent-reported). ${ }^{[26]}$ However, $94 \%$ of infants and toddlers were reported to exceed screen-time guidelines (no screen time for $<2$-year-olds), ${ }^{[24,25]}$ and TV time was positively associated with BMI $z$-scores ${ }^{[34]}$ Although this study was conducted in children below the target age group, it highlights a potential problem for the subsequent preschool years. Based on limited evidence and equivocal findings in this age group, the grade is inconclusive.

INC There are no recent data reporting on fitness levels in children and adolescents, so the grade has been changed to INC.

C- $\quad$ There are very few data on the proportion of parents or peers supporting PA, but recent evidence ${ }^{[35]}$ seems to support previous findings regarding the importance of parent support (but indicate that this may be limited), so the grade remains a C-.

D- New evidence indicates that the proportion of children participating in school PE is still sub-optimal, and that the policy-implementation gap is widening. In ISCOLE, SA was the country (out of 12) with the greatest proportion of learners not participating in $\mathrm{PE}(32 \%) \cdot{ }^{[36]}$ There seems to be no clear evidence of progress in the prioritisation of PE in the school curriculum or environment at a national level. The grade has therefore been downgraded to a D-.

C- $\quad$ In ISCOLE, children living in unsafe areas with a high traffic risk did less MVPA after school in neighbourhoods (mostly low income) ${ }^{[37]}$ Although various community engagement and civil society initiatives address the safety of children in communities, these efforts appear to be taking place in a small number of locations. The grade therefore remains a C-.

C The Sport and Recreation SA National School Sport Programme remained a core deliverable in the 2016 - 2017 strategic plan, and with commitment from the National Department of Basic Education, aimed to maximise access to sport, recreation and PA in every school in SA. However, compliance with this programme appears to remain poor, and there is a lack of documented evidence of policy implementation and evaluation. There is also no evidence of new PA or sport policies influencing children and adolescents. The grade has therefore been downgraded to a $\mathrm{C}$. 
Table 4. HAKSA 2018 nutrition grades and rationale

\section{Nutrition \\ indicator}

Fruit and

vegetable intake

Snacking, SSBs,

dietary sodium,

fast food

School nutrition D-

culture and

environment

NSNP

Food security

D-

Advertising and Dmedia

D

\section{Grade Rationale}

The national survey of the NSNP indicated that only $21.4 \%$ of schools served the recommended quantity of fruit and vegetables. ${ }^{[38]}$ No other studies were found relating to this grade. The grade therefore remains a D.

Despite the bleak economic climate in SA, the fast food stores count indicates a growth of about $4.8 \%$ over 2017 while the sale of soft drinks and fruit juices increased by $7.5 \%$ and $12.7 \%$, respectively, in $2016 .{ }^{[39]}$ The ISCOLE study reported that SA children consumed $>4$ SSBs per week, and had the highest intake of all countries in the study. ${ }^{[40]}$ Furthermore, children in the lowest income groups had higher odds for 'unhealthy dietary pattern' scores than children in the highest socioeconomic status groups. ${ }^{[41]}$ The new Sugary Beverages Levy ('sugar tax') has been effective since 1 April 2018 in SA, while the manufacturing of food products with lower salt levels was implemented in 30 June 2016 and further reductions will be effective from 2019. In response to the sugar tax, the largest manufacturer of soft drinks in SA introduced 'shrinkflation', cutting portion sizes sold per bottle/can by $\sim 10 \%$, while keeping the price the same in order to 'help people consume less sugar. ${ }^{\text {'42] }}$ Although these new fiscal measures have been promulgated with the aim of reducing sugar and salt intake, the impact on behaviour has not yet been measured. Although these policy initiatives are encouraging, the grade remains an $\mathrm{F}$.

School tuck shops, vegetable gardens and nutrition education through the school curriculum were considered for this grade. Although several guidelines and programmes to establish healthy school tuck shops are available, no regulation of implementation of these exists. Food bought from tuckshops or vendors is mostly unhealthy, with low nutrient density, high energy density and high levels of added salt and sugar. ${ }^{[43]}$ This is concerning as about $50 \%$ of school-going children in SA regularly buy food at school, and do not pack lunch boxes. ${ }^{[43]}$ The NSNP study observed that $40 \%$ of schools had food gardens that supply produce for NSNP meals, $23.9 \%$ of gardens were well maintained and $31.4 \%$ had vegetables growing in them. ${ }^{[38]}$ According to a regional qualitative study, many barriers exist that hinder the successful implementation of nutrition education in the curriculum. ${ }^{[44]}$ Since there has been insufficient progress in establishing healthy school nutrition culture and environment, a grade of D- was assigned.

The NSNP has wide reach, providing meals to $>9$ million children in public schools (all children in quintiles 1 - 3 ). A national study confirmed that $96.2 \%$ of these schools served the NSNP meal, and that $72.7 \%$ of learners were observed eating the NSNP meal on the day of data collection. However, only $47.4 \%$ of the children said they 'always', and a further $47.6 \%$ 'sometimes' eat the NSNP meal. ${ }^{[38]}$ Average expenditure per day on the NSNP was calculated as ZAR2.51 per child. ${ }^{[4]}$ There are many challenges with the implementation of the NSNP, including: children not receiving the recommended amount and type of food (as unintended beneficiaries eat NSNP meals, while grants do not make provision for this); nutrition composition of meals is mostly not in line with prescribed guidelines; food is served too late (after $10 \mathrm{~h} 00$ in $81.9 \%$ of schools) for its intended purpose of improved concentration; and health and safety concerns regarding food preparation. Furthermore, there are days (and in some cases, months) that feeding does not take place due to funds not being received on time, late delivery of foods or lack of fuel for cooking. ${ }^{[38]}$ Owing to these challenges, the grade has been downgraded to a C.

Just over half (56\%) of South Africans live on ZAR30 or less per day, while extreme poverty ( $<$ ZAR441 per person per month) increased by 2.8 million in the last 4 years. ${ }^{[4]}$ The current unemployment rate of $27.2 \%$ (June 2018) indicates no improvement over the past two decades. ${ }^{[47]}$ Furthermore, over the past 3 years the country has experienced the worst drought in more than 100 years, consequently influencing local farming produce from livestock and crops. Food inflation spiked from 10.5\% in April 2016 to $11.8 \%$ in December 2016, thereafter decreasing to its most recent level of 3.5\% in June 2018 . $^{[48]}$ The dire economic situation in SA, high unemployment and food inflation rates directly influence individual and household food security, with children aged $\leq 17$ years one of the most vulnerable groups to be affected. ${ }^{[46]}$ According to the 2016 community survey, $19.9 \%$ of households had run out of money to buy food in the previous 12 months. ${ }^{[49]}$ Mkhawani et al. ${ }^{[50]}$ reported that the rising food prices resulted in $77 \%$ of households in the Mopani District running short of food before the end of the month. One other study in a low-income setting confirmed high levels of food insecurity in children. ${ }^{\text {[51] }}$ Since the factors contributing to food insecurity appear to be worsening (or at least not improving), the grade has been downgraded to a D-.

Draft regulations (R429 of May 2014) relating to the marketing of food and beverages to children have still not been passed by government. ${ }^{[52]}$ Wiles ${ }^{[53]}$ reported that $71.4 \%$ of children's cereals are not eligible to make nutrient claims, but $85.7 \%$ had a claim on the package. The influence of marketing on children's preference of cereal is of great concern, and current legislation does not address this. Although there are some promising industry initiatives, such as the removal of sweets and chocolates from checkout points, ${ }^{[5]}$ and providing free fruit to children in some food stores, ${ }^{[55]}$ the reach of these initiatives is limited. The grade has been downgraded to a D- owing to the lack of adequate action by government and industry.

HAKSA = Healthy Active Kids South Africa; NSNP = National School Nutrition Programme; SSB = sugar-sweetened beverage; ISCOLE = International Study of Childhood Obesity, Lifestyle and the Environment.

HAKSA 2018 Report Card. The only indicators that seem positive are early childhood PA and gross motor proficiency (specifically in preschool-aged children), although further research is required to establish whether these levels are maintained as preschool-aged children transition into formal schooling. Furthermore, since a grade was not previously included for these early childhood indicators, it is not possible to state that this is an improvement. All indicators would benefit from additional research, and particularly research that is able to provide a national perspective, considering the heterogeneity that was identified for some indicators, particularly across different 
Table 5. HAKSA 20 Body composition grades and rationale

\begin{tabular}{|c|c|c|}
\hline $\begin{array}{l}\text { Body composition } \\
\text { indicator }\end{array}$ & Grade & Rationale \\
\hline $\begin{array}{l}\text { Overweight and } \\
\text { obesity }\end{array}$ & $\mathrm{D}$ & $\begin{array}{l}\text { The SADHS reported that } 16.1 \% \text { of girls and } 6.1 \% \text { of boys aged } 15-19 \text { years old were overweight. }{ }^{[56]} \text { Obesity } \\
\text { prevalence in } 15 \text { - } 19 \text {-year olds was } 10.9 \% \text { in girls and } 2.5 \% \text { in boys (although using adult BMI cut-offs). }{ }^{\left[{ }^{6}\right]} \text { The NIDS } \\
\text { reports a rapid rise in mean BMI in } 6 \text { - } 25 \text {-year-olds, with the highest risk in children aged } 8 \text { - } 10 \text { years old. }{ }^{[57]} \text { In this } \\
\text { study, a higher mean BMI was observed most prominently in } 8-10 \text {-year-old girls living in middle- to high-income } \\
\text { households in urban formal areas, and in low-income households in urban informal settlements. }{ }^{[57]} \text { In a rural KZN } \\
\text { study, age and sex (female) were consistently associated with increasing risk of overweight and over-fatness (>85th } \\
\text { centile body fatness). }{ }^{[58]} \text { There is significant geographic heterogeneity in overweight/obesity prevalence, and sex } \\
\text { differences (although not consistent over age groups) continue to exist. }{ }^{[56,57]} \text { Higher adiposity has been associated with } \\
\text { poor blood pressure and cardiovascular fitness measures. }{ }^{[59]} \text { Since the high prevalence of overweight/obesity persists, } \\
\text { the grade remains a D. }\end{array}$ \\
\hline Undernutrition & $\mathrm{C}$ & $\begin{array}{l}\text { Based on regional studies, undernutrition remains a problem in both rural and urban areas. }{ }^{[56,60-62]} \text { No recent } \\
\text { national data on indicators of undernutrition (stunting, wasting, underweight) are available for the } 5 \text { - } 15 \text {-year- } \\
\text { old age group. There continue to be sex differences in the prevalence of undernutrition indicators at a regional } \\
\text { level; however, these are not consistent across studies. }{ }^{[56,61,62]} \text { Socioeconomic status is inversely associated with } \\
\text { stunting, }{ }^{[56]} \text { while height-for-age is significantly associated with cognition in } 6 \text { - } 8 \text { year olds from KZN. }{ }^{[63]} \text { As } \\
\text { undernutrition still exists in children and adolescents, the grade remains a C. }\end{array}$ \\
\hline $\begin{array}{l}\text { Early childhood } \\
\text { body composition }\end{array}$ & $\mathrm{D}$ & $\begin{array}{l}\text { The SADHS (using WHO cut-offs })^{[64]} \text { reported a prevalence of overweight of } 9.1 \% \text { among } 3 \text { - } 5 \text {-year-old children. } \\
\text { The prevalence of stunting in this age group was particularly high }(21.5 \% \text { stunted, } 5.3 \% \text { severely stunted), although } \\
\text { the prevalence of wasting was low }(3.0 \%) .{ }^{[56]} \text { One study conducted across income settings (using IOTF cut-offs) } \\
\text { reported a } 19.0 \% \text { prevalence of thinness (defined as a low BMI-for-age) and } 8.9 \% \text { prevalence of overweight/obesity } \\
\text { in preschool-aged children, with urban low-income children faring the worst with respect to overweight/obesity } \\
\left(16.5 \% \mathrm{v} .<5 \% \text { in other settings). }{ }^{[23]} \text { In the absence of improvements, the grade remains a D. }\right.\end{array}$ \\
\hline
\end{tabular}

Table 6. Comparison of 2014, 2016 and 2018 HAKSA Report Card grades

\begin{tabular}{llll}
\hline Indicator & 2014 & 2016 & 2018 \\
\hline Physical activity & & & \\
Overall physical activity & D & C & C \\
Early childhood physical activity & - & INC & A- \\
Organised sport participation & C & D & D \\
Active play & INC & INC & INC \\
Active transportation & C & C & C \\
Sedentary behaviours & F & F & F \\
Early childhood sedentary behaviour & - & - & INC \\
Physical fitness & - & D & INC \\
Family and peer support & INC & C- & C- \\
School & D & D & D- \\
Community and environment & D- & C- & C- \\
Government & B & B & C \\
Nutrition & & & \\
Fruit and vegetable intake & C & D & D \\
Snacking, SSBs, dietary sodium & F & F & F \\
Fast food intake & - & F & \\
School nutrition culture and environment & & & D- \\
School tuck shop & D- & INC & - \\
Vegetable gardens & - & C & - \\
NSNP & B & B & C \\
Food security & - & D & D- \\
Advertising and media & D & D & D- \\
Body composition & & & \\
Overweight/obesity & D & D & D \\
Undernutrition & C & C & C \\
Early childhood body composition & - & D & D
\end{tabular}

HAKSA = Healthy Active Kids South Africa; SSB = sugar-sweetened beverage; NSNP = National School Nutrition Programme; INC = inconclusive. income settings. There are challenges in measuring and reporting on the prevalence of certain behaviours and activities, e.g. active play, organised sports participation and PA at school. It was also challenging to obtain accurate data on SA children and adolescents' online exposure to food and beverage marketing, specifically SSBs and fast food. As electronic media become increasingly accessible to this age group in SA, along with increased uptake and use of social media and the global shift towards digital forms of marketing, it is more important than ever to track this exposure and its potential impact on behaviour.

Despite the absence of new evidence of improvements or declines in any of the PA, nutrition and body composition indicators between 2016 and 2018, certain indicators have been downgraded (as described in Tables 3 and 4) since the 2016 Report Card. These include PA indicators for school and government, and nutrition indicators for the NSNP, food security and advertising and media. The purpose of downgrading these indicators was to highlight the lack of progress in these areas, in the hope that relevant stakeholders and industry would take necessary action. In particular, the development and implementation of policies on PA and nutrition in the school environment, and on advertising and media relating to unhealthy eating, are needed. The food insecurity indicator was also downgraded, to highlight the lack of sufficient effort to improve access to food of adequate quality for those living in the poorest of circumstances in SA. For children and adolescents specifically, failure to act could have significant consequences for cognitive development and academic outcomes. ${ }^{[7]}$ The worsening of food insecurity is particularly concerning in light of the growth of the fast food industry and increases in SSB sales.

The HAKSA 2018 Report Card findings highlight a number of key priorities that require action. Firstly, safety remains a concern for SA children and adolescents, particularly in low-income communities: it was raised as an issue for three of the PA indicators: 'active play', 'active transportation' and 'community and environment'. There is an apparent lack of a systematic approach to deal with this issue. While further research is required to fully understand the nature of 
the impact of safety concerns on children's PA and play, children's safety and vulnerability should be a priority on a far broader agenda than this.

Secondly, there remains a significant gap between policy and implementation, particularly with regard to the school environment and government strategies to promote PA and healthy nutrition among children and adolescents. It appears that there is little accountability for lack of implementation, and that what has been implemented has not been rigorously evaluated.

Thirdly, the double burden of under- and over-nutrition persists among SA children and adolescents. Overweight/obesity continues to be high (especially among girls), despite the presence of food insecurity, which again highlights the need for better access to food of good quality, rather than merely food of high caloric content. However, this will remain challenging as the fast food industry grows, and if the sale of SSBs continues to rise. Furthermore, it is essential to consider the broader food environment and the food and beverage industry as a whole, and the impact that these may have on the nutrition and body composition of SA children and adolescents. The competitive nature of multinational food companies, their rapid penetration of markets in low- and middle-income countries and their targeting of children and parents in an effort to develop taste preferences early in life warrant consideration. ${ }^{[66]}$ There is a broader need in SA to address food environments, and how these can be adapted to support children and adolescents to make healthy food choices, in order to improve overall child health and support growth. ${ }^{[67]}$

In terms of limitations of the present review article, certain data that have been included should be interpreted with caution. These include self-report PA data, which are likely to be less reliable than objective measures. They also include the body composition data presented by the SA Demographic and Health Survey (SADHS) ${ }^{[56]}$ for adolescents, which used adult BMI cut-offs. Furthermore, the early childhood body composition data from the SADHS present much lower levels of overweight (9.1\%) than the SA National Health and Nutrition Examination Survey (SANHANES; 18.2\%), ${ }^{[68]}$ which used International Obesity Task Force cut-offs, ${ }^{[65]}$ for this age group. In addition, owing to limited prevalence data, conclusions have mostly been drawn based on smaller, regional studies.

\section{Conclusion}

The HAKSA 2018 Report Card provides an evidence-based call to action for all those with a vested interest in the health, development and wellbeing of SA children and adolescents. With the rising prevalence of overweight/obesity and non-communicable diseases in SA adults, ${ }^{[56]}$ the need to establish healthy lifestyle behaviours and promote environments that support healthy choices among children and adolescents is more important than ever. A healthier generation of young South Africans could contribute to the progress and development of our country.

Acknowledgements. In addition to the listed authors, the HAKSA 2018 Report Card Scientific Advisory Group consists of: C Burnett (University of Johannesburg), CJ Christie (Rhodes University), CJ Cook (University of Cape Town), C Cozett (University of the Western Cape), M de Milander (University of the Free State), H Dugmore (Rhodes University), M Faber (SA Medical Research Council), S Krog (University of South Africa), T Liebenberg (Sports Science Institute of SA), Z Mchiza (University of the Western Cape), K McQuaide (Sports Science Institute of SA), ST Meltzer (Sports Science Institute of SA), N Naidoo (University of Cape Town), R Naidoo (University of KwaZulu-Natal), A Prioreschi (University of the Witwatersrand), AE Pienaar (North-West University), T Puoane (University of the Western Cape), B Tromp (SA Heart and Stroke
Foundation), M van Gent (University of Fort Hare), C Walter (Nelson Mandela University), E Watson (University of the Witwatersrand).

Author contributions. CED and EVL were co-leaders of the HAKSA 2018 Report Card. CED co-ordinated the scientific advisory group and the compilation of the final lay report, and drafted the manuscript. SAT conducted the literature searches and helped to co-ordinate the review process. In the Scientific Advisory Group, SHB and AM were leaders of the PA group; JH led the nutrition group; and HSK and LKM co-ordinated the body composition group. All authors edited and commented on the manuscript and approved the final version.

Funding. None.

Conflicts of interest. None

1. Carson V, Lee E-Y, Hewitt L, et al. Systematic review of the relationships between physical activity and health indicators in the early years $(0-4$ years). BMC Public Health 2017;17(S5):40-31. http://doi.org/10.1186/s12889-017-4860-0

2. Poitras VJ, Gray CE, Borghese MM, et al. Systematic review of the relationships between objectively measured physical activity and health indicators in schoolaged children and youth. Appl Physiol Nutr Metab 2016;41(6 Suppl 3):S197-S239. http://doi.org/10.1139/apnm-2015-0663

3. Carson V, Hunter S, Kuzik N, et al. Systematic review of sedentary behaviour and health indicators in school-aged children and youth: An update. Appl Physiol Nutr Metab 2016;41(6 Suppl 3):S240-S265. http://doi.org/10.1139/apnm-2015-0630

4. Poitras VJ, Gray CE, Janssen X, et al. Systematic review of the relationships between sedentary behaviour and health indicators in the early years $(0-4$ years). BMC Public Health 2017;17(S5):540-525. http://doi.org/10.1186/s12889-017-4849-8

5. Pate RR, O'Neill JR, Liese AD, et al. Factors associated with development of excessive fatness in children and adolescents: A review of prospective studies. Obes Rev 2013;14(8):645-658. http://doi.org/10.1111/obr.12035

6. Van Horn L, Banks L, Vincent E, McCrindle BW. The importance of nutrition and physical activity for children. Pediatr Ann 2012;41(2):67-72. http://doi. org/10.3928/00904481-20120110-10

7. Martin A, Booth JN, Laird Y, Sproule J, Reilly JJ, Saunders DH. Physical activity diet and other behavioural interventions for improving cognition and school achievement in children and adolescents with obesity or overweight. Cochrane Database Syst Rev 2018;3(2):CD009728. http://doi.org/10.1002/14651858. CD009728.pub3

8. Statistics South Africa. Census 2011. Pretoria: Statistics South Africa, 2012. http://www.statssa.gov.za/census/census_2011/census_products/Census_2011_ Methodology_and_Highlights_of_key_results.pdf (accessed 20 January 2019).

9. IndexMundi. IndexMundi - country facts. https://www.indexmundi.com (accessed 20 January 2019).

10. Uys M, Bassett S, Draper CE, et al. Results From South Africa's 2016 Report Card on physical activity for children and youth. J Phys Act Health 2016;13(11 Suppl 2):S265-S273. http://doi.org/10.1123/jpah.2016-0409

11. Steyn NP, Nel JH, Parker W, Ayah R, Mbithe D. Urbanisation and the nutrition transition: A comparison of diet and weight status of South African and Kenyan women. Scand J Public Health 2012;40(3):229-238. http://doi. org/10.1177/1403494812443605

12. Draper CE, Basset S, de Villiers A, Lambert EV, Writing Group H. Results From South Africa's 2014 report card on physical activity for children and youth. J Phys Act Health 2014;11(4 Suppl 1):S98-S104. http://doi.org/10.1123/jpah.2014-0185

13. Aubert S, Barnes JD, Abdeta C, et al. Global Matrix 3.0 Physical activity report card grades for children and youth: Results and analysis from 49 countries. J Phys Act Health 2018;15(S2):S251-S273. http://doi.org/10.1123/jpah.2018-0472

14. Loney PL, Chambers LW, Bennett KJ, Roberts JG, Stratford PW. Critical appraisa of the health research literature: Prevalence or incidence of a health problem. Chronic Dis Can 1998;19(4):170-176.

15. Muthuri SK, Onywera VO, Tremblay MS, et al. Relationships between Parental education and overweight with childhood overweight and physical activity in 9-11 year old children: Results from a 12-country study. PLoS ONE 2016;11(8):e0147746. http://doi.org/ 10.1371/journal.pone.0147746

16. Roman-Viñas B, Chaput J-P, Katzmarzyk PT, et al. Proportion of children meeting recommendations for 24-hour movement guidelines and associations with adiposity in a 12-country study. Int J Behav Nutr Phys Act 2016;13:1-10. http://doi.org/10.1186/s12966-016-0449-8

17. Sampasa-Kanyinga H, Standage M, Tremblay MS, et al. Associations between meeting combinations of 24-hour movement guidelines and health-related quality of life in children from 12 countries. Public Health 2017;153:16-24. http:// doi.org/10.1016/j.puhe.2017.07.010

18. Van Biljon A, McKune AJ, DuBose DK, Kolanisi U, Semple SJ. Physical activity levels in urban-based South African learners: A cross-sectional study of 7 348 participants. S Afr Med J 2018;108(2):126-131. http://doi.org/10.7196/ SAMJ.2018.v108i2.12766

19. Van Niekerk L-L, du Toit D, Pienaar AE. The correlation between motor proficiency and physical activity in Senior Phase learners in the Potchefstroom area. Health SA Gesondheid 2016;21:348-355. http://doi.org/10.1016/j. hsag.2016.05.001 
20. Salvini M. Physical activity and health-related quality of life among schoolchildren from disadvantaged neighbourhoods in Port Elizabeth, South Africa. Qual Life Res 2017;27(1):205-216. http://doi.org/10.1007/s11136-017-1707-1

21. Tibbits MK, Caldwell LL, Smith EA, Vergnani T, Wegner L. Longitudinal patterns of active leisure among South African youth: Gender differences and associations with health risk behaviours. World Leisure J 2015;58(1):60-68. http://doi.org/10. 1080/16078055.2015.1089317

22. Tremblay MS, LeBlanc AG, Carson V, et al. Canadian physical activity guidelines for the early years (aged 0 - 4 years). Appl Physiol Nutr Metab 2012;37(2):345-56.

23. Draper CE, Tomaz SA, Stone M, et al. Developing intervention strategies to optimise body composition in early childhood in South Africa. Biomed Res Int 2017;2017(1):5283457. http://doi.org/10.1155/2017/5283457

24. Tremblay MS, Chaput J-P, Adamo KB, et al. Canadian 24-hour movement guidelines for the early years (0-4 years): An integration of physical activity, sedentary behaviour, and sleep. BMC Public Health 2017;17(S5):S15-S32. http:// doi.org/10.1186/s12889-017-4859-6

25. Okely AD, Ghersi D, Hesketh KD, et al. A collaborative approach to adopting/ adapting guidelines - the Australian 24-hour movement guidelines for the early years (birth to 5 years): An integration of physical activity, sedentary behavior and sleep. BMC Public Health 2017;17(S5):370-324. http://doi.org/10.1186/s12889017-4867-6

26. Tomaz SA. Physical activity and gross motor skills in rural South African preschool children. PhD thesis. Cape Town: University of Cape Town, 2018. https://open.uct.ac.za/handle/11427/29464 (accessed 8 March 2018).

27. Van Heerden A, Hsiao C, Matafwali B, Louw J, Richter L. Support for the feasibility of the ages and stages questionnaire as a developmental screening tool: A crosssectional study of South African and Zambian children aged $2-60$ months. BMC Pediatrics 2017;17(1):55. http://doi.org/10.1186/s12887-017-0802-3

28. Figueroa R, Saltzman J, Jarick Metcalfe J, Wiley A. 'Culture is so interspersed': Child-minders' and health workers' perceptions of childhood obesity in South Africa. J Obes 2017;2017(2):1-14. http://doi.org/10.1155/2017/9629748

29. Stone M. Perceptions of physical activity in preschool-aged children in urban and rural samples in South Africa. MA thesis. Cape Town: University of Cape Town 2016. https://open.uct.ac.za/handle/11427/20652 (accessed 8 March 2018).

30. Bartie M, Dunnell A, Kaplan J, et al. The play experiences of preschool children from a low-socioeconomic rural community in Worcester, South Africa. Occup Ther Int 2015;23(2):91-102. http://doi.org/10.1002/oti.1404

31. Koekemoer K, van Gesselleen $M$, van Niekerk A, Govender R, van As AB. Child pedestrian safety knowledge, behaviour and road injury in Cape Town, South Africa. Acc Anal Prev 2017;99(A):202-209. http://doi.org/10.1016/j. aap.2016.11.020

32. Simons A, Koekemoer K, Niekerk AV, Govender R. Parental supervision and discomfort with children walking to school in low-income communities in Cape Town, South Africa. Traffic Inj Prev 2018;19(4):391-398. http://doi.org/10.1080/ 15389588.2017.1420904

33. Dietrich JJ, Laher F, Hornschuh S, et al. Investigating sociodemographic factors and HIV risk behaviors associated with social networking among adolescents in Soweto, South Africa: A cross-sectional survey. JMIR Public Health Surveill 2016;2(2):e154. http://doi.org/10.2196/publichealth.4885

34. Prioreschi A, Brage S, Hesketh KD, Hnatiuk J, Westgate K, Micklesfield LK. Describing objectively measured physical activity levels, patterns and correlates in a cross-sectional sample of infants and toddlers from South Africa. Int J Behav Nutr Phys Activity 2017;14:176. http://doi.org/10.1186/s12966-017-0633-5

35. Cozett C, Bassett SH, Leach L. Factors influencing participation in physical activity among 11- 13-year-old school children in the Western Cape, South Africa. Afr J Phys Health Edu Recreation Dance 2016;22(4):21-28.

36. Silva DAS, Chaput JP, Katzmarzyk PT, et al. Physical education classes, physica activity, and sedentary behavior in children. Med Sci Sports Exerc 2018;50(5):9951004. http://doi.org/10.1249/MSS.0000000000001524

37. Uys M, Broyles ST, Draper CE, et al. Perceived and objective neighborhood support for outside of school physical activity in South African children. BMC Public Health 2016;16(1):462. http://doi.org/10.1186/s12889-016-2860-0

38. Hazell E. Report on the implementation evaluation of the National School Nutrition Programme. Pretoria: JET Education Services, 2016. https:// evaluations.dpme.gov.za/evaluations/528 (accessed 8 March 2018).

39. Wesgro. Beverages. Cape Town: Wesgro, 2016. http://www.wesgro.co.za/pdf repository/2016_06\%20Beverages.pdf (accessed 20 June 2018)

40. Katzmarzyk P, Broyles S, Champagne C, et al. Relationship between soft drink consumption and obesity in 9 - 11-year-old children in a multinational study. Nutrients 2016;8(12):770-713. http://doi.org/10.3390/nu8120770

41. Manyanga T, Tremblay MS, Chaput J-P, et al. Socioeconomic status and dietary patterns in children from around the world: Different associations by levels of country human development? 2017;17:457. http://doi.org/10.1186/s12889-0174383-8

42. Child K. Smaller soft drink sizes leave bitter taste of shrinkflation. Johannesburg. TimesLive, 2017. https://www.timeslive.co.za/news/consumer-live/2017-10-25smaller-soft-drink-sizes-leave-bitter-taste-of-shrinkflation/ (accessed 20 June 2018).

43. Nortje N, Faber M, de Villiers A. School tuck shops in South Africa - an ethical appraisal. S Afr J Clin Nutr 2016;30(3):74-79. http://doi.org/10.1080/16070658.2 017.1267401

44. Nguyen KA, de Villiers A, Fourie JM, Hendricks M. Challenges to implementing the food-based dietary guidelines in the South African primary school curriculum: A qualitative study exploring the perceptions of principals and curriculum advisors. S Afr J Clin Nutr 2016;30(1):15-20. http://doi.org/10.1080 /16070658.2016.1230971
45. Gresse A, Nomvete A, Walter C. Situational analysis: Implementation of the National School Nutrition Programme in low socioeconomic primary schools in Nelson Mandela Bay. J Consumer Sci 2017;2:59-68.

46. Statistics South Africa. Poverty trends in South Africa. Pretoria: Pretoria: StatsSA, 2017. https://www.statssa.gov.za/publications/Report-03-10-06/ Report-03-10-062015.pdf (accessed 20 June 2018).

47. Statistics South Africa. Quarterly labour force survey. Pretoria: StatsSA, 2018 http://www.statssa.gov.za/?p=11361 (accessed 5 August 2018).

48. Trading Economics. South Africa food inflation. Trading Economics, 2018 https://tradingeconomics.com/south-africa/food-inflation (accessed 20 June 2018).

49. Statistics South Africa. Community survey 2016. Pretoria: StatsSA, 2016. http:// www.statssa.gov.za/?page_id=6283 (accessed 5 August 2018).

50. Mkhawani K, Motadi SA, Mabapa NS, Mbhenyane XG, Blaauw R. Effects of rising food prices on household food security on female-headed households in Runnymede Village, Mopani District, South Africa. S Afr J Clin Nutr 2016;29(2):69-74. http://doi.org/10.1080/16070658.2016.1216504

51. Hendriks SL, van der Merwe C, Ngidi MS, et al. What are we measuring? Comparison of household food security indicators in the Eastern Cape Province, South Africa. Ecol Food Nutr 2016;55(2):141-162. http://doi.org/10 $.1080 / 03670244.2015 .1094063$

52. National Department of Health, South Africa. Draft guidelines: Labelling and advertising offoods.Pretoria:NDoH,2014.http://www.health.gov.za/index.php/ shortcodes/2015-03-29-10-42-47/2015-04-30-09-10-23/2015-04-30-09-11-35/ category/36-documents-for-comment (accessed 8 March 2018).

53. Wiles NL. The nutritional quality of South African ready-to-eat breakfast cereals. S Afr J Clin Nutr 2017;30(4):93-100. http://doi.org/10.1080/16070658 .2017.1319124

54. BUSINESSTECH. Half of all Woolworths Food stores have moved sweets away from the checkout line. 2016. https://businesstech.co.za/news/lifestyle/134074/ half-of-all-woolworths-food-stores-have-moved-sweets-away-from-thecheckout-line (accessed 20 June 2018).

55. Media24. Free fruit for kids when shopping at Pick n Pay. Johannesburg: Media24, 2018. https://www.w24.co.za/SelfCare/Wellness/Mind/free-fruit-forkids-when-shopping-at-pick-n-pay-20181004 (accessed 20 June 2018).

56. National Department of Health, Statistics South Africa, South African Medical Research Council, ICF. South Africa Demographic and Health Survey 2016: Key indicators. Pretoria: NDoH, Stats SA, SAMRC, ICF, 2017. https://www. statssa.gov.za/publications/Report\%2003-00-09/Report\%2003-00-092016.pdf (accessed 8 March 2018).

57. Sartorius B, Sartorius K, Taylor M, et al. Rapidly increasing body mass index among children, adolescents and young adults in a transitioning population, South Africa, 2008 - 2015. Int J Epidemiol 2017;47(3):942-952. http://doi. org/10.1093/ije/dyx263

58. Craig E, Reilly JJ, Bland R. Risk factors for overweight and overfatness in rural South African children and adolescents. J Public Health 2016;38(1):24-33. http://doi.org/10.1093/pubmed/fdv016

59. Awotidebe A, Monyeki MA, Moss SJ, Strydom GL, Amstrong M, Kemper HCG. Relationship of adiposity and cardiorespiratory fitness with resting blood pressure of South African adolescents: The PAHL Study. J Hum Hypertens 2016;30(4):245-251. http://doi.org/10.1038/jhh.2015.81

60. Nyathela T, Oldewage-Theron W. Nutritional status and food consumption patterns of primary school children in Orange Farm. Afr J Food Agric Nutr Dev 2017;17(1):11497. http://doi.org/10.18697/ajfand.77.12155

61. Oldewage-Theron W, Kruger R. The association between diet quality and subclinical inflammation among children aged 6 - 18 years in the Eastern Cape, South Africa. Pub Health Nutr 2016;20(1):102-111. http://doi.org/10.1017/ S1368980016001956

62. Ngwenya NA, Ramukumba TS. Prevalence of adolescent obesity at a high school in the City of Tshwane. Curationis 2017;40(1):S193-S197. http://doi. org/10.4102/curationis.v40i1.1662

63. Ajayi OR, Matthews G, Taylor M, et al. Factors associated with the health and cognition of 6-year-old to 8-year-old children in KwaZulu-Natal, South Africa. Trop Med Int Health 2017;22(5):631-637. http://doi.org/10.1111/tmi.12866

64. World Health Organization. Application tools. Geneva: WHO, 2009. http:// www.who.int/growthref/tools/en/ (accessed 8 March 2018).

65. Cole TJ, Lobstein T. Extended international (IOTF) body mass index cut-offs for thinness, overweight and obesity. Pediatr Obes 2012;7:284-94. http://doi. org/10.1111/j.2047-6310.2012.00064.x

66. Lobstein T, Jackson-Leach R, Moodie ML, et al. Child and adolescent obesity: Part of a bigger picture. Lancet 2015;385(9986):2510-2520. http://doi. org/10.1016/S0140-6736(14)61746-3

67. Hawkes C, Smith TG, Jewell J, et al. Smart food policies for obesity prevention. Lancet 2015;385(9985):2410-2421. http://doi.org/10.1016/S01406736(14)61745-1

68. Shisana O, Labadarios D, Rehle T, et al. South African National Health and Nutrition Examination Survey (SANHANES-1). Cape Town: HSRC Press, 2013. http://www.hsrc.ac.za/uploads/pageNews/72/SANHANES-launch\%20 edition\%20(online\%20version).pdf (accessed 8 March 2018). 